Case Report

\title{
Transitory Fetal Skin Edema in a Pregnant Patient with a Mild SARS-CoV-2 Infection
}

\author{
Alicia Martínez-Varea (D), Julia Desco-Blay, Sagrario Monfort, María Hueso-Villanueva, \\ Alfredo Perales-Marín $(\mathbb{D}$, and Vicente José Diago-Almela

\begin{abstract}
Department of Obstetrics and Gynecology, University and Polytechnic La Fe Hospital, Avenida Fernando Abril Martorell 106,
\end{abstract} \\ 46026 Valencia, Spain
}

Correspondence should be addressed to Alicia Martínez-Varea; martinez.alicia.v@gmail.com

Received 24 January 2021; Revised 11 February 2021; Accepted 3 March 2021; Published 16 March 2021

Academic Editor: Edi Vaisbuch

Copyright (C) 2021 Alicia Martínez-Varea et al. This is an open access article distributed under the Creative Commons Attribution License, which permits unrestricted use, distribution, and reproduction in any medium, provided the original work is properly cited.

\begin{abstract}
Background. Vertical transmission of the Coronavirus Disease 2019 (COVID-19) is still controversial. Additionally, the consequences of the infection during pregnancy in the offspring also are unknown. Case. A transitory fetal skin edema and polyhydramnios have been demonstrated by ultrasound in a pregnant patient with COVID-19 after a negative RT-PCR for SARS-CoV-2. The fetal findings presented a spontaneous resolution in utero, and abnormal findings were not found in the newborn. Conclusion. Women who have undergone SARS-CoV-2 infection during pregnancy should receive a subsequent appropriate follow-up in order to clarify the fetal consequences of the novel coronavirus, if any.
\end{abstract}

\section{Introduction}

The ongoing pandemic is caused by the severe acute respiratory syndrome coronavirus 2 (SARS-CoV-2), which was initially identified in Wuhan, China, at the end of 2019 [1]. Due to its remarkably contagious behavior [2], the novel coronavirus has infected over 114 million people worldwide [3]. Mainly transmitted through respiratory droplets, it leads to pneumonia [4], and the clinical course of severe or critical SARS-CoV-2 infection in hospitalized pregnant women may be shorter than in nonpregnant patients [5].

Not only is vertical transmission of the Coronavirus Disease 2019 (COVID-19) still controversial [6-18], but the fetal consequences of the infection during pregnancy also are unknown $[7,19,20]$. It has been recently reported fetal transient skin edema in two pregnant women while they showed positive reverse-transcription polymerase chain reaction (RT-PCR) test results for SARS-CoV-2 infection [21]. At our tertiary hospital, a transitory fetal skin edema and polyhydramnios were demonstrated by ultrasound in a pregnant patient with a mild infection after a negative RTPCR for SARS-CoV-2.

\section{Case Report}

A 22-year-old gravida 2, para 1 woman at $283 / 7$ weeks' gestation presented to the emergency department at $\mathrm{La} \mathrm{Fe}$ University and Polythecnic Hospital (Valencia, Spain) with a 3-day history of mucus and shortness of breath. Neither fever nor cough were shown. Her partner had been admitted into the hospital 24 hours before due to pneumonia and a positive RT-PCR test for SARS-CoV-2. The pregnancy was spontaneously conceived and uneventful, with a low risk first trimester screening for trisomies 21,18 , and 13 , as well as a normal fetal anatomy visualized at the 20 weeks' morphological ultrasound. Physical examination revealed a body mass index, temperature, blood pressure, respiratory rate, and hemoglobin saturation by pulse oximetry within normal limits. Blood tests showed a D-dimer level of $1680 \mathrm{ng} / \mathrm{ml}$, and the remainder parameters were within the normal range. The patient tested positive for SARS-CoV-2 infection on RTPCR of nasopharyngeal swabs. A chest radiograph revealed the absence of abnormal images, and the fetal ultrasound was reassuring. Hence, she was discharged and her wellbeing was assessed every $48-72$ hours by phone calls. The 
TABLE 1: In-person follow-up of the pregnant woman after the PCR for SARS-CoV-2 was negative.

\begin{tabular}{lcccc}
\hline $\begin{array}{l}\text { Gestational age at } \\
\text { ultrasound (weeks) }\end{array}$ & $\begin{array}{c}\text { Estimated fetal } \\
\text { weight }(\mathrm{g})\end{array}$ & $\begin{array}{c}\text { Maximum vertical pocket of } \\
\text { amniotic fluid }(\mathrm{mm})\end{array}$ & $\begin{array}{c}\text { Peak systolic } \\
\text { velocity }(\mathrm{cm} / \mathrm{seg})\end{array}$ & Fetal anomalies \\
\hline $350 / 7$ & 2645 & 81 & 57 & $\begin{array}{c}\text { None } \\
363 / 7\end{array}$ \\
2789 & 86 (Figure 2) & 54 & $\begin{array}{c}\text { Fetal skin edema (11 mm) was visualized } \\
\text { only in the head (Figure 1) } \\
373 / 7\end{array}$ \\
$383 / 7$ & 3500 & 88 & 55 & $\begin{array}{c}\text { Fetal skin edema (4 mm) in the axial plane } \\
\text { of the head } \\
\text { None }\end{array}$ \\
\hline
\end{tabular}

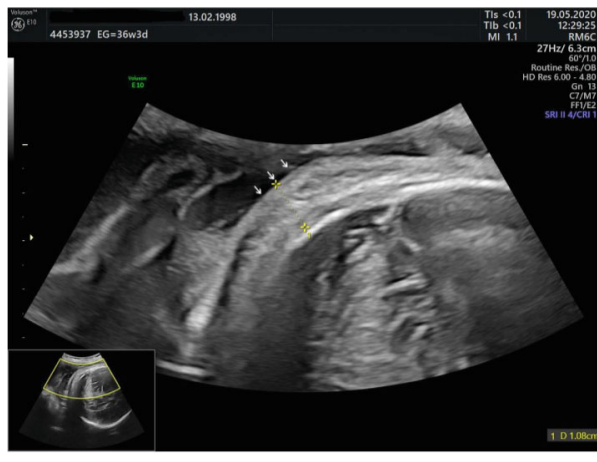

(a)

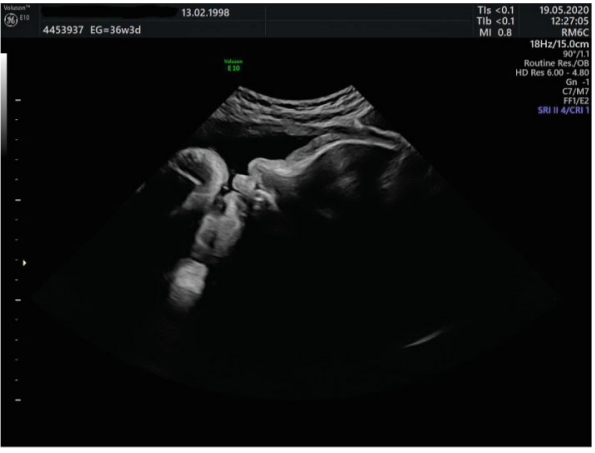

(b)

Figure 1: (a) A transitory fetal skin edema $(11 \mathrm{~mm}$ ) was visualized in the axial plane of the fetal head by ultrasound at $363 / 7$ weeks of pregnancy. (b) Sagittal view of the transitory fetal head skin edema at $363 / 7$ weeks of pregnancy.

symptoms of infection lasted for a total of 10 days, and the RT-PCR for SARS-CoV-2 became negative at 32 6/7 weeks. IgG and IgM antibodies were negative in maternal serum at $326 / 7$ weeks.

The fetal ultrasound at $350 / 7$ weeks gestation revealed an estimated fetal weight in accordance with the gestational age $(2645 \mathrm{~g})$ and a maximum vertical pocket of amniotic fluid of $81 \mathrm{~mm}$ (Table 1). The subsequent follow-up with serial ultrasounds revealed a transitory fetal skin edema $(11 \mathrm{~mm}$ in the axial plane of the head at 36 3/7 weeks, Figures 1(a) and 1(b); and $4 \mathrm{~mm}$ at $373 / 7$ weeks gestation), as well as polyhydramnios (maximum vertical pocket $86 \mathrm{~mm}$ at $363 / 7$ weeks, Figure 2; and $88 \mathrm{~mm}$ at $373 / 7$ weeks gestation). Peak systolic velocity remained within normal limits. Maternal serology was negative, and the glucose level was normal. Both developed a spontaneous resolution. IgG and IgM antibodies remained negative in maternal serum at $383 / 7$ weeks. In the ultrasound at $383 / 7$ weeks gestation, no fetal skin edema of the head was seen, the estimated fetal weight was $3500 \mathrm{~g}$, and the maximum vertical pocket of amniotic fluid was $76 \mathrm{~mm}$. The patient underwent a spontaneous vaginal delivery at 39 4/7 weeks of pregnancy. The female newborn weighted 3700 g, associated an Apgar Score 10/10, an arterial pH 7.28, and a venous $\mathrm{pH}$ 7.33. Neither cord blood PCR nor antibodies were assessed. Both, the mother and the newborn, were healthily discharged 48 hours after birth.

\section{Discussion}

Pregnant women are particularly vulnerable to infections due to their relative immunosuppressed state and restricted

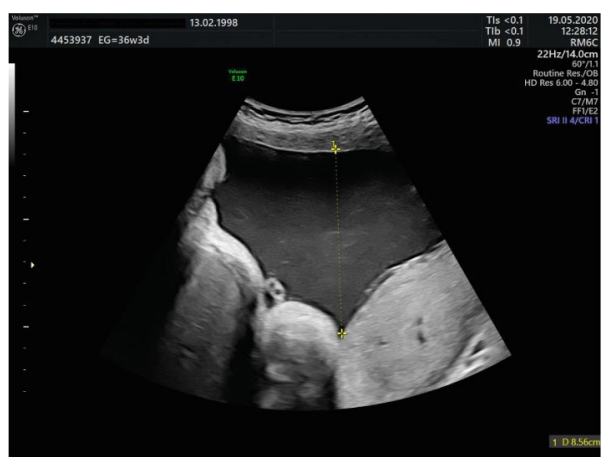

Figure 2: Polyhydramnios (maximum vertical pocket $86 \mathrm{~mm}$ at 36 $3 / 7$ weeks of pregnancy).

cardiorespiratory capacity [22]. Nonetheless, it has not been described that pregnant women have a predisposition to SARS-CoV-2 infection or that those with the infection are more susceptible to develop severe pneumonia [23]. The infection is severe or critical in $9 \%$ and $5 \%$ of pregnant women, respectively [24], and these percentages are similar to those of nonpregnant patients [25].

Regarding the adverse maternal and perinatal outcomes associated with COVID-19, preterm delivery is the most common adverse pregnancy outcome among women with severe disease $[5,23,26]$. As far as the risk of vertical transmission is concerned, although it remains controversial [6-18], placental infection by SARS-CoV-2 has been recently demonstrated $[6,16,18]$. Two cases of fetal transient skin edema during the second trimester of pregnancy in women with COVID-19 have been recently described, being the pregnancy outcome 
unknown given that the patients were still pregnant at the time of the publication [21]. The authors hypothesized that these findings might constitute the expression of fetal infection or the consequence of the maternal infection in the fetal physiology [21]. The current case report describes a transitory fetal skin edema associated with polyhydramnios in a pregnant woman with COVID-19 after the RT-PCR testing for SARS$\mathrm{CoV}-2$ was negative. The fetal findings presented a spontaneous resolution in utero, and abnormal findings were not found in the newborn. Neither RT-PCR testing nor IgG and IgM antibodies were performed to the neonate. Although causes of fetal hydrops such as gestational diabetes or other viral infections were ruled out in our patient, further fetal assessment by ultrasound in pregnant women with COVID-19 are required to elucidate whether these fetal findings are common and if they entail any consequence in the offspring.

In conclusion, these findings support the need of a close monitoring of women who have undergone SARS-CoV-2 infection during pregnancy in order to completely understand the fetal consequences of the novel coronavirus. Additionally, it remains essential the assessment of the umbilical cord blood of the newborn, either PCR or antibodies, from those mothers who have undergone COVID-19 during pregnancy.

\section{Ethical Approval}

Ethics committee approval was unnecessary due to the nature of the study.

\section{Consent}

Verbal consent has been obtained from the patient to share with the scientific community of the present case report. No written consent has been obtained from the patient as there is no patient identifiable data included in this case report.

\section{Conflicts of Interest}

The authors report no conflicts of interest.

\section{References}

[1] N. Zhu, D. Zhang, W. Wang et al., "A novel coronavirus from patients with pneumonia in China, 2019," The New England Journal of Medicine, vol. 382, no. 8, pp. 727-733, 2020.

[2] J. F. W. Chan, S. Yuan, K. H. Kok et al., "A familial cluster of pneumonia associated with the 2019 novel coronavirus indicating person-to-person transmission: a study of a family cluster," Lancet, vol. 395, no. 10223, pp. 514-523, 2020.

[3] University, J H, COVID-19 Dashboard by the Center for Systems Science and Engineering (CSSE) at Johns Hopkins University (JHU), 2020, https://coronavirus.jhu.edu/map.html.

[4] S. A. Rasmussen, J. C. Smulian, J. A. Lednicky, T. S. Wen, and D. J. Jamieson, "Coronavirus disease 2019 (COVID-19) and pregnancy: what obstetricians need to know," American Journal of Obstetrics and Gynecology, vol. 222, no. 5, pp. 415-426, 2020.

[5] R. A. M. Pierce-Williams, J. Burd, L. Felder et al., "Clinical course of severe and critical coronavirus disease 2019 in hospi- talized pregnancies: a United States cohort study," American Journal of Obstetrics \& Gynecology MFM, vol. 2, no. 3, article 100134, 2020.

[6] G. N. Algarroba, P. Rekawek, S. A. Vahanian et al., "Visualization of severe acute respiratory syndrome coronavirus 2 invading the human placenta using electron microscopy," American Journal of Obstetrics and Gynecology, vol. 223, no. 2, pp. 275278, 2020.

[7] M. C. Alzamora, T. Paredes, D. Caceres, C. M. Webb, L. M. Valdez, and M. La Rosa, "Severe COVID-19 during pregnancy and possible vertical transmission," American Journal of Perinatology, vol. 37, no. 8, pp. 861-865, 2020.

[8] O. Celik, A. Saglam, B. Baysal et al., "Factors preventing materno-fetal transmission of SARS-CoV-2," Placenta, vol. 97, pp. 1-5, 2020.

[9] H. Chen, J. Guo, C. Wang et al., "Clinical characteristics and intrauterine vertical transmission potential of COVID-19 infection in nine pregnant women: a retrospective review of medical records," Lancet, vol. 395, no. 10226, pp. 809-815, 2020.

[10] L. Dong, J. Tian, S. He et al., "Possible vertical transmission of SARS-CoV-2 from an infected mother to her newborn," Journal of the American Medical Association, vol. 323, no. 18, pp. 1846-1848, 2020.

[11] X. Hu, J. Gao, X. Luo et al., "Severe acute respiratory syndrome coronavirus 2 (SARS-CoV-2) vertical transmission in neonates born to mothers with coronavirus disease 2019 (COVID-19) pneumonia," Obstetrics and Gynecology, vol. 136, no. 1, pp. 65-67, 2020.

[12] M. Karimi-Zarchi, H. Neamatzadeh, S. A. Dastgheib et al., "Vertical transmission of coronavirus disease 19 (COVID19) from infected pregnant mothers to neonates: a review," Fetal and Pediatric Pathology, vol. 39, no. 3, pp. 246-250, 2020.

[13] A. Lamouroux, T. Attie-Bitach, J. Martinovic, M. Leruez-Ville, and Y. Ville, "Evidence for and against vertical transmission for severe acute respiratory syndrome coronavirus 2," American Journal of Obstetrics and Gynecology, vol. 223, no. 1, pp. 91.e1-91.e4, 2020.

[14] Y. Li, R. Zhao, S. Zheng et al., "Lack of vertical transmission of severe acute respiratory syndrome coronavirus 2, China," Emerging Infectious Diseases, vol. 26, no. 6, pp. 1335-1336, 2020.

[15] D. Lu, L. Sang, S. du, T. Li, Y. Chang, and X. A. Yang, "Asymptomatic COVID-19 infection in late pregnancy indicated no vertical transmission," Journal of Medical Virology, vol. 92, no. 9, pp. 1660-1664, 2020.

[16] C. A. Penfield, S. G. Brubaker, M. A. Limaye et al., "Detection of severe acute respiratory syndrome coronavirus 2 in placental and fetal membrane samples," American Journal of Obstetrics \& Gynecology MFM, vol. 2, no. 3, article 100133, 2020.

[17] A. J. Vivanti, C. Vauloup-Fellous, S. Prevot et al., "Transplacental transmission of SARS-CoV-2 infection," Nature Communications, vol. 11, no. 1, p. 3572, 2020.

[18] P. Zhang, C. Salafia, T. Heyman, C. Salafia, S. Lederman, and B. Dygulska, "Detection of severe acute respiratory syndrome coronavirus 2 in placentas with pathology and vertical transmission," American Journal of Obstetrics \& Gynecology MFM, vol. 2, no. 4, article 100197, 2020.

[19] J. Juan, M. M. Gil, Z. Rong, Y. Zhang, H. Yang, and L. C. Poon, "Effect of coronavirus disease 2019 (COVID-19) on maternal, perinatal and neonatal outcome: systematic review," 
Ultrasound in Obstetrics \& Gynecology, vol. 56, no. 1, pp. 1527, 2020

[20] A. M. Kotlyar, O. Grechukhina, A. Chen et al., "Vertical transmission of coronavirus disease 2019: a systematic review and meta-analysis," American Journal of Obstetrics and Gynecology, vol. 224, no. 1, pp. 35-53.e3, 2021.

[21] P. Garcia-Manau, I. Garcia-Ruiz, C. Rodo et al., "Fetal transient skin edema in two pregnant women with coronavirus disease 2019 (COVID-19)," Obstetrics and Gynecology, vol. 136, no. 5, pp. 1016-1020, 2020.

[22] A. Panchaud, G. Favre, L. Pomar et al., "An international registry for emergent pathogens and pregnancy," Lancet, vol. 395, no. 10235, pp. 1483-1484, 2020.

[23] L. C. Poon, H. Yang, A. Kapur et al., "Global interim guidance on coronavirus disease 2019 (COVID-19) during pregnancy and puerperium from FIGO and allied partners: information for healthcare professionals," International Journal of Gynaecology and Obstetrics, vol. 149, no. 3, pp. 273-286, 2020.

[24] N. Breslin, C. Baptiste, C. Gyamfi-Bannerman et al., "Coronavirus disease 2019 infection among asymptomatic and symptomatic pregnant women: two weeks of confirmed presentations to an affiliated pair of New York City hospitals," American Journal of Obstetrics \& Gynecology MFM, vol. 2, no. 2, article 100118, 2020.

[25] Z. Wu and J. M. McGoogan, "Characteristics of and important lessons from the coronavirus disease 2019 (COVID-19) outbreak in China," Journal of the American Medical Association, vol. 323, no. 13, pp. 1239-1242, 2020.

[26] D. di Mascio, A. Khalil, G. Saccone et al., "Outcome of coronavirus spectrum infections (SARS, MERS, COVID-19) during pregnancy: a systematic review and meta-analysis," American Journal of Obstetrics \& Gynecology MFM, vol. 2, no. 2, article 100107, 2020. 